\title{
Space weather influences on atmospheric electricity
}

Article

Accepted Version

Nicoll, K. A. (2014) Space weather influences on atmospheric electricity. Weather, 69 (9). pp. 238-241. ISSN 1477-8696 doi: https://doi.org/10.1002/wea.2323 Available at https://centaur.reading.ac.uk/55389/

It is advisable to refer to the publisher's version if you intend to cite from the work. See Guidance on citing.

To link to this article DOI: http://dx.doi.org/10.1002/wea.2323

Publisher: Wiley

All outputs in CentAUR are protected by Intellectual Property Rights law, including copyright law. Copyright and IPR is retained by the creators or other copyright holders. Terms and conditions for use of this material are defined in the End User Agreement.

\section{www.reading.ac.uk/centaur}

\section{CentAUR}

Central Archive at the University of Reading

Reading's research outputs online 


\title{
Space weather influences on atmospheric electricity
}

\author{
K.A. Nicoll
}

Department of Meteorology, University of Reading

\section{The atmospheric electrical environment}

Atmospheric electricity is a venerable topic of geophysical science, dating back to the 1750s when Franklin and Dalibard established the presence of electricity in thunderstorms. Subsequently even fine conditions were observed to be electrified, and a downward vertical atmospheric electric field of magnitude $\sim 100 \mathrm{~V} / \mathrm{m}$ observed near the surface during fair weather conditions ${ }^{1}$. The origin of the "fair weather field" remained unknown the pioneering electrical measurements of the geophysical survey ship Carnegie in the 1920s, which demonstrated a diurnal variation in the electric field aligned with universal time rather than local time. This characteristic variation remains known as the "Carnegie Curve" and was subsequently demonstrated as similar to the diurnal variation in global thunderstorm area. This supported the idea of a "Global atmospheric Electric Circuit" (GEC), postulated by CTR Wilson (Wilson 1929; Harrison, 2011), through which charge separation in thunderstorms sustains large scale current flow around the world and the fair weather field, now confirmed by Blakeslee et al (2014). Figure 1 represents the GEC. The Earth's surface and the lower ionosphere (at approximately $60 \mathrm{~km}$ altitude) are represented as two oppositely charged "electrodes) of a spherical capacitor, within which air provides a leaky dielectric. Charge transfer from thunderclouds, rain and lightning continuously electrify the ionosphere to a potential $250 \mathrm{kV}$ more positive than Earth's surface, known as the ionospheric potential, $\mathrm{V}_{\mathrm{i}}$.

Atmospheric air is conductive due to the presence of cluster ions, which are created primarily from Galactic Cosmic Rays, GCRs, highly energetic Hydrogen or Helium nuclei ( $\sim \mathrm{GeV}$ energy) from outside our solar system, and also, near the surface, from Earth's natural radioactivity. As GCRs enter Earth's atmosphere, they create a cascade of ions as they interact with atmospheric molecules. The conductive nature of air means that the potential difference between the ionosphere and the Earth's surface is associated with a return current, known as the air-Earth conduction current density, $\mathrm{J}_{\mathrm{c}}$. This vertical current flows globally in fair weather regions, between the ionosphere and the surface. In the vertical dimension, Ohms' law relates $J_{c}$ to $V_{i}$ and the total resistance of a unit area column of air from the ionosphere to the surface, $R_{c}$, by

$$
J_{c}=\frac{V_{i}}{R_{c}}
$$

The columnar resistance, $R_{c}$, is related to the conductivity of the vertical atmospheric column, where $\sigma(z)$ is the air conductivity at altitude $z$. $R_{c}$ is found by integrating the resistance of atmospheric layers from the surface to the ionosphere, by evaluating

$$
R_{c}=\int_{0}^{\infty} \frac{d z}{\sigma(z)}
$$

\footnotetext{
${ }^{1}$ Fair weather conditions are those in which no local charge separation processes are occurring.
} 
The conductivity, $\sigma$, is directly proportional to the ionisation rate and, above the surface, depends principally on the GCR flux entering Earth's atmosphere. (This can be measured at the surface using a neutron monitor ${ }^{2}$.)

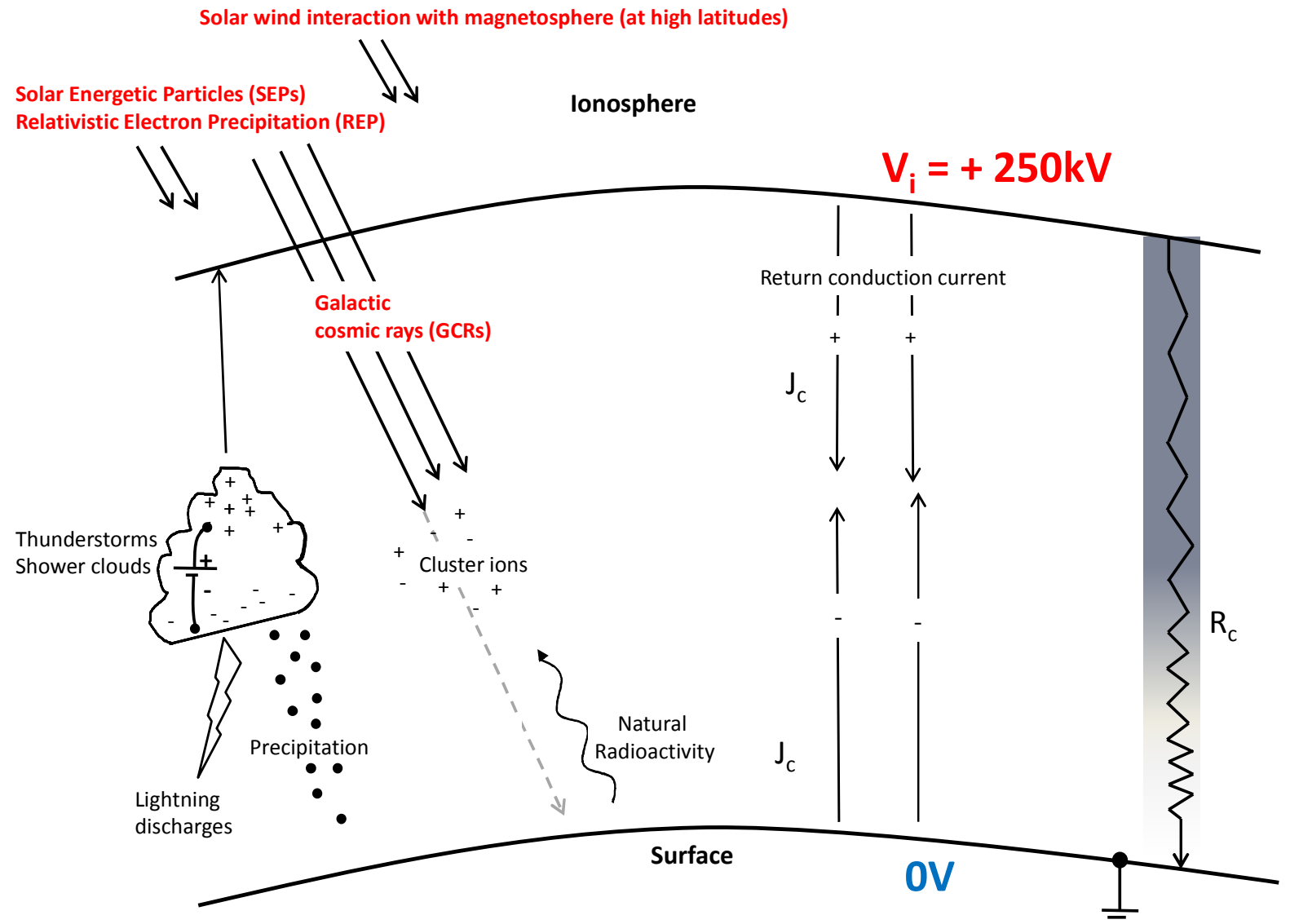

Figure 1. Atmospheric charge generation and transport, including important processes in the global electric circuit. Thunderstorms and electrified shower clouds act as batteries for the circuit, with the current carried by cluster ions, generated by radioactivity and galactic cosmic rays. $J_{c}$ denotes the vertical conduction current density, $R_{c}$ the columnar resistance, and the shaded bar characterises the change in potential with altitude, from a value of OV at Earth's surface to $+250 \mathrm{kV}$ in the ionosphere. Processes known to be related to space weather are depicted in red. Adapted from Rycroft et al (2012).

\section{Atmospheric electricity and space weather}

Earth's electrical environment is influenced by external as well as internal drivers, including the global charging current from thunderstorms (dependent on the number and strength of thunderstorms, and ENSO), and global aerosol concentrations and cloud cover, which can increase the columnar resistance, $R_{c}$. The external influences (identified in red in Figure 1), form the remainder of this discussion, which result from a variety of different space weather phenomenon including variations in the solar magnetic field, geomagnetic ${ }^{3}$ field variations and ionisation changes

\footnotetext{
${ }^{2}$ Neutron monitors detect the secondary neutron component of the GCR particle cascade at the surface. There is currently a worldwide neutron monitor network spanning a variety of geomagnetic latitudes.

${ }^{3}$ The term "geomagnetic field" refers to Earth's magnetic field.
} 
from Solar Energetic Particles (SEPs) and GCRS. From equations (1.) and (2.) it follows that a change in either $\sigma$ or $V_{i}$ will result in a change in the global conduction current $J_{c}$. To understand the various mechanisms by which space weather may influence atmospheric electricity, the following section discuss space weather effects on $\sigma$ and $V_{i}$.

\section{(a) Conductivity changes}

A variety of space weather related phenomena can modify the ionisation rate and therefore affect the conductivity, $\sigma$. The GCR flux arriving at Earth, which is responsible for most of the ionisation in Earth's atmosphere, is modulated by the geomagnetic field, as well as the solar magnetic field, which has an 11 year cycle but also varies transiently due to coronal mass ejections (CMEs) and solar flares. The solar magnetic field acts like a barrier to GCRs, therefore during a CME, stronger magnetic field irregularities in the solar wind can cause enhanced scattering of incoming GCRs, causing a sudden decrease in the GCR flux at Earth, known as a Forbush decrease.

Free balloon measurements by Gringel (1978) demonstrated how the conductivity decreased down to altitudes of $10 \mathrm{~km}$ over Germany on $8^{\text {th }}$ August 1972 , following solar flares on $2^{\text {nd }}$, $4^{\text {th }}$ and $7^{\text {th }}$ of August, corroborated by a decrease of $20 \%$ in the GCR flux measured by a neutron monitor at Oulu, Finland. Effects of Forbush decreases on surface atmospheric electrical parameters are also evident in a decrease in the electric field (e.g. in Hungary (of $10 \mathrm{~V} / \mathrm{m}$ ), Märcz (1997)), using a superposed epoch analysis technique to combine multiple events.

During energetic solar events such as solar flares, large numbers of Solar Energetic Particles (SEPs, mostly protons) can enter Earth's atmosphere, with the geomagnetic latitude and altitude they can penetrate down to depending on their energy. Most primary protons of energy less than $500 \mathrm{MeV}$ are absorbed above $15 \mathrm{~km}$, however primary protons of energy $>500 \mathrm{MeV}$ will generate a cascade of secondary particles through interactions with atmospheric molecules. On rare occasions, when the primary SEPS have energies $\approx \mathrm{GeV}$, the secondaries can be of sufficient energy to reach ground level, causing a Ground Level Event (GLE). Relativistic electron precipitation (REP) (keV to MeV) provides an additional source of ionisation down to altitudes of $\sim 50 \mathrm{~km}$, however the associated X-ray Bremsstrahlung produces ionization down to about $20 \mathrm{~km}$ (Fram et al., 1997). Increases in ionisation rate from SEPs and REP are highly latitude dependent as geomagnetism modulates particle penetration into the atmosphere, allowing greater particle flux at high latitudes from reduced geomagnetic shielding at the magnetic poles. Figure 2 demonstrates the normal ionisation profile measured in the atmosphere due to GCR ionisation (black line) and its enhancement for a hypothetical SPE event at different periods during the event (red and blue lines). Developments in technology mean that ionisation sensors can now be flown alongside standard meteorological radiosondes, as exemplified by the sensors developed at the University of Reading (Harrison et al, 2013), (inset Figure 2). This opens up new opportunities for space weather monitoring by using existing radiosonde flights, in the relatively understudied, but potentially very important, zone between Earth's surface and satellites.

The effects of SEP events on atmospheric electrical variables can be seen directly from the balloon measurements of Kokorowski et al (2006) and Holzworth et al (1987), the latter detected a decrease in the magnitude of electric field and increase in conductivity (by a factor of 2 ) at $26 \mathrm{~km}$. A second balloon at similar altitude but further towards the geomagnetic equator showed no detectable electrical changes, allowing the spatial extent of the SEP event on the electrical environment to be 
determined. Although the effects of SEPs on atmospheric electrical parameters can be appreciable at high altitudes and at high latitudes, their effects on the GEC are smaller. As suggested by Holzworth and Mozer (1979) and supported by model simulations of the August 1972 SEP event by Reagan et al (1983), the largest changes in GEC parameters ( $10 \%$ in $V_{i}, J_{z}$ and electric field) are related to the change in GCR flux during the Forbush decrease, with little effect of the SEP event on the GEC.

Increased ionisation from SEPs can also potentially lead to changes in the internal global charging current from thunderstorms, which is dependent on stratospheric/mesospheric resistance above a thunderstorm. Model calculations by Farrell and Desch (2002) find that, during large SEP events, the resistance above thunderstorms can decrease sufficiently to increase the upward charging current to the ionosphere. This can affect $J_{c}$ as well as the surface electric field, however, changes in electric field for even the biggest SEP events are only expected to be $~ 5 \%$.

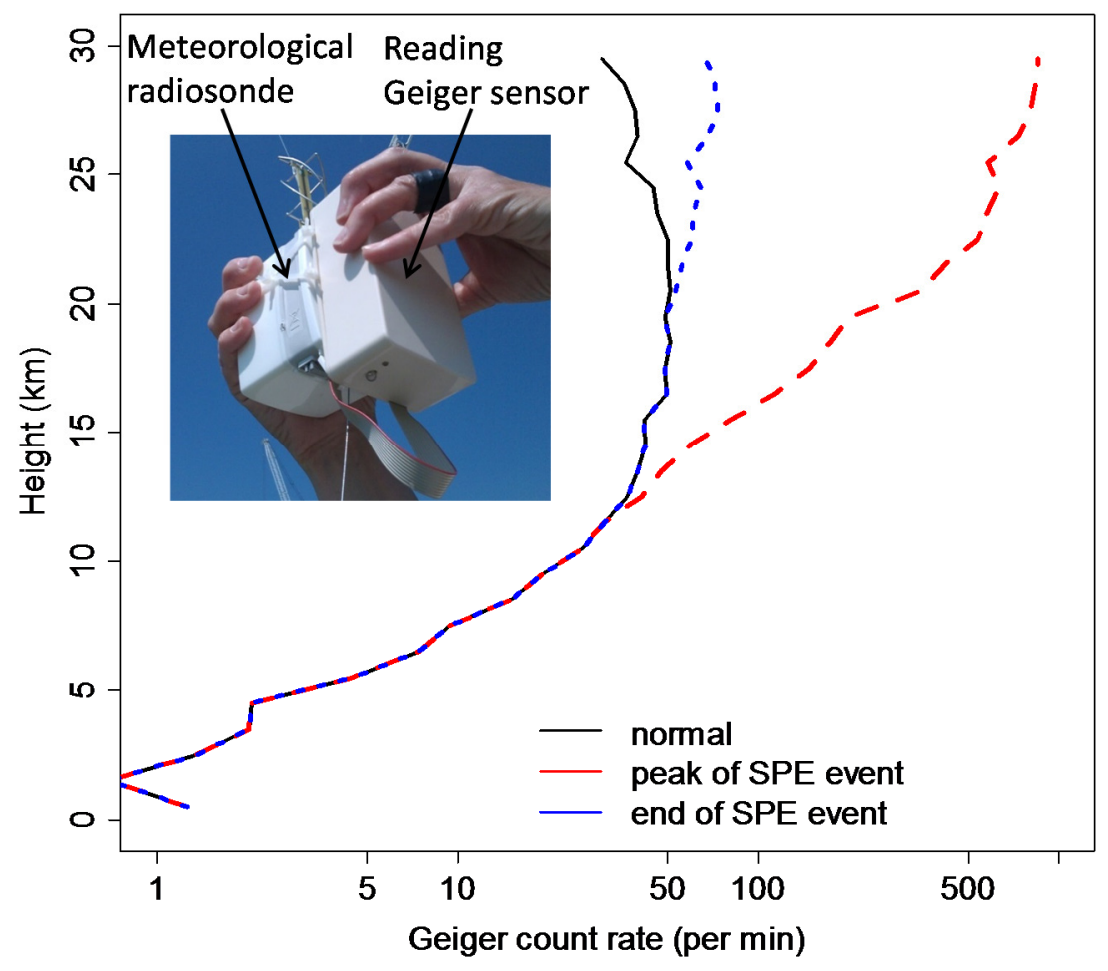

Figure 2. Ionisation measurements from balloon borne Geiger sensor (showing Geiger count rate) flown from Reading, UK, alongside a standard meteorological radiosonde. The black line denotes the normal ionisation profile due to background GCRs and the red and blue lines, hypothetical profiles at the peak and end of an SPE event respectively. The Geiger count rate is related to the ionisation rate, which in turn relates to the atmospheric electricity parameters of air conductivity and columnar resistance. 


\section{(b) Ionospheric potential changes}

At high latitudes electrical coupling occurs between the magnetospheric ${ }^{4}$ dynamo and the global electric circuit at high altitudes. The ionosphere is considered an equipotential, except over the polar regions, where the solar wind interacts with the geomagnetic field to produce large scale horizontal electric fields in the ionosphere (sometimes known as the solar wind/magnetosphere dynamo). Horizontal fields of sufficiently large horizontal extent $(500-1000 \mathrm{~km})$ can effectively map down to the surface, creating perturbations in vertical electric field near the ground (Park, 1976). Such effects are only present at high latitudes, within $30^{\circ}$ of the poles, and horizontal $V_{i}$ variations between dawn-dusk are typically 30-150kV (Roble, 1985). Stratospheric balloon measurements of electric fields show that, during magnetically quite periods, the classical Carnegie curve is apparent in electric field data, however during more active geomagnetic periods the dawn-dusk potential difference of the magnetospheric convection pattern is seen, superimposed on the Carnegie curve (D’Angelo et al., 1982).

Evidence of transfer of magnetospheric disturbances into the troposphere at high latitudes can be seen through the surface electric field measurements of Olson (1971) as well as at mid latitudes through the work of Kleimenova et al (2008), who demonstrated surface electric field responses to magnetic substorms ${ }^{5}$ from Swider, Poland.

Magnetospheric disturbances can also result in precipitation of relativistic electrons (keV energies), which typically occur at auroral and subauroral latitudes during magnetic substorms and can enhance the conductivity down to the ionospheric $D$ layer ${ }^{6}$. This may lead to redistribution of downward atmospheric current, generating perturbations in surface measurements of $\mathrm{J}_{\mathrm{c}}$ (Belova et al., 2000).

\section{(c) Lightning generation}

Measurements in thunderstorms indicate that the electric field strength is an order of magnitude too small to initiate conventional breakdown in air, implying that a more complicated breakdown process occurs. One possible explanation is that GCRs may directly trigger lightning through a mechanism known as "runaway breakdown" when electrons generated in the particle cascade are accelerated to relativistic energies, developing an electron avalanche which leads to breakdown (e.g. Roussel-Dupré et al., 2008). Research by Chronis (2009) demonstrated a decrease in lightning activity 4-5 days after a Forbush decrease in GCR, suggesting that GCRs may play a role in lightning generation, although much more work is required to understand the timescales involved. Unfortunately work in this field is hampered by high levels of natural variability in thunderstorm occurrence and lightning flash rates, and difficulties with obtaining reliable and consistently calibrated lightning data.

\footnotetext{
${ }^{4}$ The term "magnetospheric" here refers to the region of space around Earth in which charged particles are controlled by the Earth's magnetic field

${ }^{5}$ Magnetic substorms occur due to a redistribution of ionospheric electric field from electric currents in the ionosphere. They are primarily observed over the poles and occur regularly (several times a day, but the exact timings are solar cycle dependent).

${ }^{6}$ The $\mathrm{D}$ layer is the lowest region of the ionosphere (approximately $60-85 \mathrm{~km}$ )
} 


\section{Atmospheric electrical effect on clouds}

Although evidence of a space weather influence on atmospheric electrical parameters exists, the solar-electrical coupling mechanisms are not fully understood. This is required to assess the consequences of vertical conduction current flow through clouds (e.g. Tinsley (2000), Zhou and Tinsley (2007)), which has been observed to charge cloud droplets at the upper and lower boundaries of layer clouds (Nicoll and Harrison, 2010). Electrification of the cloud droplets can have implications for cloud microphysical processes (see e.g. Rycroft et al (2012)), and potentially provides one source of variability in the macroscopic properties of clouds. The sensitivity of the vertical conduction current to variations in solar activity may provide a route by which space weather changes can couple down through the lower atmosphere to the surface and affect tropospheric processes.

\section{Summary}

This paper summarises the various mechanisms by which space weather is thought to affect atmospheric electricity on Earth. These include ionisation changes from GCRs and SEPs which affect the vertical conductivity profile; interactions between the solar wind and magnetosphere generating horizontal ionospheric electric fields which couple down to the surface; changes in ionospheric conductivity due to precipitating electrons; and lightning generation from energetic particles. Although this discussion has separated mechanisms into those which affect conductivity or the ionospheric potential, in reality most space weather events are a complicated superposition of both of these effects. This means that although evidence of a space weather influence on atmospheric electrical parameters exists, the coupling mechanisms are not well understood. Further work is required to understand the role of changes in the "disturbed weather" i.e. thunderstorms and "fair weather" part of the circuit, both of which are likely to contribute to changes observed in atmospheric electrical parameters. To further understand the effects of space weather on the GEC, which may in turn also influence clouds, more measurements of atmospheric electrical responses to short term solar perturbations are required, with high temporal resolution measurements, over a wide range of geomagnetic latitudes. New developments in atmospheric technology allow in situ measurement of ionisation rates from GCRs and SEPs simultaneously with atmospheric electrical parameters (Nicoll, 2013) from standard meteorological radiosondes, facilitating new low cost space weather monitoring in the troposphere and stratosphere using the existing operational radiosonde network. Such observations are important to assess the effects of atmospheric electricity on layer clouds, which provides a route by which changes in space weather may couple to lower tropospheric processes.

\section{Acknowledgements}

KAN acknowledges the support of a Leverhulme Trust Early Career Fellowship, and STFC project ST/K001965/1 ("Airborne monitoring of space weather and radioactivity"). Prof. R.G. Harrison has also provided many useful discussions on this topic. 


\section{References}

Belova E., S. Kirkwood and H. Tammet, 2000, The effect of magnetic substorms on near-ground atmospheric current, Ann. Geophysicae, 18, 1623-1629.

Blakeslee,R.J., D. M. Mach, M. G. Bateman, J. C. Bailey, 2014, Seasonal variations in the lightning diurnal cycle and implications for the global electric circuit, Atmos. Res., 135-136,228-243.

Chronis T., 2009, Investigating possible links between incoming cosmic ray fluxes and lightning activity over the United States, J. Clim., 22, 5748-5754

D'Angelo N., I.B. Iversen and M.M. Madsen, 1982, Influences of the dawn-dusk potential drop across the polar cap on the high-latitude atmospheric vertical current, Geophys. Res., Lett., 9, 773776.

Farrell, W.M. and M.D. Desch, 2002, Solar proton events and the fair weather electric field at ground, Geophys. Res. Lett., 29, 9, 1323.

Fram, R.A., Winningham, J.D., Sharber, J.R., et al., 1997, The diffuse aurora: A significant source of ionization in the middle atmosphere, J. Geophys. Res. 102, 28,203-28,214.

Gringel, W., 1978, Untersuchungen zur elektrischen Luftleitfahigkeit unter Berucksichtihung der Sonnenaktivitat und der Aerosolteilchenkonzentration bis $35 \mathrm{~km}$ Hohe. PhD Thesis, Universitat Tubingen.

Harrison, R. G., 2011, The cloud chamber and CTR Wilson's legacy to atmospheric science. Weather, $66,276-279$.

Harrison, R.G., K.A. Nicoll, K.A. McWilliams, 2013, Space weather driven changes in lower atmosphere phenomena, J. Atmos. and Sol.-Terr. Phys., 98, 22-30.

Harrison, R. G., Nicoll, K. A. and Lomas, A. G., 2013, Geiger tube coincidence counter for lower atmosphere radiosonde measurements,. Rev. Sci. Instrum , 84, 076103.

Holzworth, R. H., Mozer F. S., 1979. Direct evidence of solar flare modification of stratospheric electric fields, J. Geophys. Res. 84, 363-367

Holzworth, R. H., Norville K. W., Williamson, P. R., 1987. Solar flare perturbations in stratospheric current systems, Geophys. Res., Lett., 14, 852-855

Kleimenova,N.G., O.V. Kozyreva, S. Michnowski, M. Kubicki, 2008, Effect of magnetic storms in variations in the atmospheric electric field at mid latitudes, Geomagnetism and Aeronomy, 48, 5, 650-659.

Kokorowski, M., Sample, J. G., Holzworth, R. H., 2006, Rapid fluctuations of stratospheric electric field following a solar energetic particle events, Geophys. Res., Lett, 33, L20105.

Märcz F., 1997, Short term changes in atmospheric electricity associated with Forbush decreases, J. Atmos and Sol. Terr.Phys., 59, 9, 975-982

Nicoll, K.A., 2013, A self-calibrating electrometer for atmospheric charge measurements from a balloon platform, Rev. Sci. Instrum., 84, 096107.

Nicoll, K.A., R.G. Harrison, 2010, Experimental determination of layer cloud edge charging from cosmic ray ionisation, Geophys. Res. Lett.,37, L13802.

Olson D.E. , 1971, The evidence for auroral effects on atmospheric electricity. Pure Appl. Geophys., 84, 118-138.

Park, C.G., 1976, Downward mapping of high-latitude electric fields to the ground, J. Geophys. Res., 81, 168-174.

Reagan, J.B., R.E. Meyerott, J.E. Evans, W.L. Imhof, 1983, The effects of energetic particle precipitation on the atmospheric electric circuit, J. Geophys. Res. 88, 3869-3878.

Roble, R.G., 1985, On solar-terrestrial relationships in atmospheric electricity, J. Geophys. Res., 90, D4, 6000-6012. 
Roussel-Dupré R., Colman J.J., Symbalisty E., et al, 2008, Physical processes related to discharges in planetary atmospheres, Space Sci. Revs., 137, 1-4, 51-82

Rycroft, M.J., Nicoll K.A., Aplin, K.L., et al., 2012. Recent advances in global electric circuit coupling between the space environment and the troposphere, J. Atmos. and Sol.Terr. Phys., 90-91, 198-211.

Tinsley, B.A., 2000. Influence of solar wind on the global electric circuit, and inferred effects on cloud microphysics, temperature and dynamics in the troposphere. Space Sci. Rev. 94, 231258.

Wilson C.T.R., 1929. Some thundercloud problems, J. Franklin Inst, 20, 1-12.

Zhou, L., Tinsley, B.A., 2007. Production of space charge at the boundaries of layer clouds. J. Geohpys. Res 112, D11203. 